\title{
The pediatric asymptomatic SARS-CoV-2 IgG seropositivity in the Turkish Republic of Northern Cyprus
}

\author{
Umut Gazi $^{1 \oplus}$, Ayşe Arıkan Sarıoğlu ${ }^{1,2}$, Emrah Ruh ${ }^{1 \oplus}$, Burçin Şanlıdağ $\breve{~}^{3 \oplus}$, \\ Ceyhun Dalkan ${ }^{3 \odot}$, İlke Beyitler ${ }^{3 \oplus}$, Kaya Süer $^{4 \oplus}$, Nedim Çakır ${ }^{1,4 \oplus}$, Murat Sayan ${ }^{2,5}$, \\ Tamer Şanlıdağ ${ }^{2 \odot}$ \\ ${ }^{1}$ Department of Medical Microbiology and Clinical Microbiology, ${ }^{3}$ Department of Paediatrics, ${ }^{4}$ Department of Infectious Diseases and \\ Clinical Microbiology, Faculty of Medicine, Near East University, Nicosia, Cyprus; ${ }^{2}$ DESAM Research Institute, Near East University, \\ Nicosia, Cyprus; ${ }^{5}$ PCR Unit, Educational and Research Hospital of Kocaeli University, Kocaeli University Kocaeli, Turkey.
}

\begin{abstract}
Background. While children were initially thought to have serious contributions to the coronavirus disease 2019 (COVID-19) transmission, recent studies suggest otherwise. However, the possible effect of asymptomatic pediatric spread still has not yet received enough attention. The aim of our study was to estimate asymptomatic infection rates among children in the Turkish Republic of Northern Cyprus, by using pediatric patients admitted to a university hospital without any COVID-19-associated symptoms.
\end{abstract}

Methods. Blood samples collected from 80 pediatric patients with no symptoms and history of COVID-19 infection, who were admitted to a university hospital between September 2020 and January 2021, were included in the retrospective study. Isolated serum samples were tested by Dia.Pro SARS-CoV-2 IgG ELISA assays.

Results. The patient group included 40 (50\%) male and $40(50 \%)$ female patients. The average age of children was $7.6 \pm 4.0$ years, with min-max ages ranging from 2 to 15 years. Among the 80 patients tested, only one (1.3\%) was detected positive by the Dia.Pro IgG ELISA kit.

Conclusions. The asymptomatic seropositivity reported in our study suggests the use of randomly performed serologic tests to monitor SARS-CoV-2 infection among the pediatric population in schools that would contribute to the public health fight against COVID-19.

Key words: SARS-CoV-2, serology, seropositivity, IgG, children.

Since its first detection in March 2020, there have been more than 2,600 cases and at least 14 deaths that were officially attributed to Coronavirus Disease 2019 (COVID-19), caused by severe acute respiratory syndrome coronavirus 2 (SARS-CoV-2), in the Turkish Republic of Northern Cyprus (TRNC). While COVID-19 spread was under control, thanks to the nonpharmaceutical interventions implemented ${ }^{1}$ during the early stages of the pandemic, lifting some control measures in the second half of the

\footnotetext{
Umut Gazi

umut.gazi@neu.edu.tr
}

Received 20th April 2021, revised 24th May 2021, accepted 26th July 2021. year resulted in a continuously elevated number of confirmed cases, that still continues today. ${ }^{2}$

One control measure implemented globally was school closure to reduce social contact between children. The data motivating this implementation was mainly based on past experiences with influenza outbreaks, for which children were the major transmitters. While the SARS-CoV-2 transmission dynamic appears to be different since current accumulating evidence suggests children are not the major driver of COVID-19 spread and are rarely involved in secondary transmission ${ }^{3,4}$, this was also thought to be due to lower testing and exposure in children, which should be addressed for more reliable conclusions. ${ }^{5}$ Today, more attention has 
been drawn on pediatric transmission due to an increased number of cases and the emergence of new variants of the virus. ${ }^{6,7}$ Initial studies conducted early in the pandemic regarded children as the 'silent spreaders' of SARS$\mathrm{CoV}-2$ due to the higher rate of asymptomatic COVID-19 infection in the pediatric population than that reported for adults., ${ }^{4,8}$ However, despite data on the asymptomatic spread of SARS-CoV-2, this mode of transmission by children, which may spread the virus for extended periods ${ }^{9}$ and can act as a potential source of undetected community transmission, has not yet received enough attention in the literature. ${ }^{4}$ This could be especially important for emerged variants of the virus with quicker transmission rates. ${ }^{10}$

The aim of our study was to retrospectively evaluate asymptomatic SARS-CoV-2 exposure among a group of pediatric patients, who were admitted to a university hospital, without any complaint associated with or any history of SARS-CoV-2 infection, in the TRNC after the school closure implementation was lifted (i.e. after September 2020). For our study, serologic testing was preferred as it can detect antibodies from both past and present infections. The results would provide data on pediatric asymptomatic infection rates that may contribute to future studies on the planning of health care policies.

\section{Material and Methods}

\section{General characteristics of the TRNC population}

According to the latest data provided by the TRNC Statistical Institution (TSI) in 2011, the total population of TRNC was reported to be 286,257 with 150,483 (52.6\%) male and 135,774 $(47.4 \%)$ female subjects. The numbers of subjects with ages of $<19$ years, $20-49$ years, $50-64$ years, $65-84$ years and $>85$ years were $73,517(25.7 \%)$; 150,105 (52.4\%); 39, 377 (13.8\%); 21, 435 (7.5\%); and $1,823(0.6 \%)$, respectively. ${ }^{11}$

\section{Ethical approval}

This retrospective study was approved by Near East University (NEU) Scientific Research and Evaluation Ethics Committee (Project No: YDU/2020/86-1226). All patient databases were obtained using the hospital information system after receiving informed consent from the parents. Absence of any past SARS-CoV-2 infection was confirmed by hospital records and interviews with parents.

\section{Serum samples}

Blood samples collected for routine testing from 80 children who were admitted to Near East University Hospital for routine control or with complaints other than those associated with COVID-19 between September 2020 and January 2021 were included in the study. Centrifuged blood specimens were stored at $4{ }^{\circ} \mathrm{C}$ until analysis. Serum samples were then separated and used for enzyme-linked immunosorbent assay (ELISA) for retrospective detection of SARS-CoV-2 IgG antibodies.

\section{ELISA}

To evaluate $\operatorname{IgG}$ production, isolated serum samples were analysed by CE-in vitro diagnostic-certified Dia.Pro COVID-19 IgG kit (Diagnostic Bioprobes, Sesto San Giovanni, Italy), following the manufacturer's guidelines. The kit is involved in detection of antibodies against SARS-CoV-2 nucleocapsid (NC) and spike (S) antigens.

The kit has sensitivity of more than $98 \%$ as indicated in the manufacturer's manual. It was also reported to have specificity and sensitivity rates between $84 \%-98 \%$ and $92 \%-$ $98 \%$, respectively, by independent studies using samples from symptomatic and asymptomatic SARS-CoV-2 reverse transcription-polymerase chain reaction (RT-PCR)-confirmed patients. ${ }^{12,13}$

\section{Results}

\section{Patient characteristics}

A total of 80 children ( 40 boys and 40 girls) who were admitted to the Near East University Hospital without any symptoms associated 
with SARS-CoV-2 infection were included in our retrospective study. The age of pediatric patients ranged between 2 and 15 years, with an average age of $7.6 \pm 4.0(\mathrm{SD})$ years.

Among those, $31(38.5 \%)$ were with a prediagnosed underlying condition including neurodevelopmental $(\mathrm{n}=11,13.8 \%)$ and nephrourological disorders $(n=10,12.5 \%)$. While $17(21.3 \%)$ children admitted to the hospital for routine check-up control, the remaining displayed complaints such as gastrointestinal $(n=20, \% 25)$, dermatologic $(n=12,15 \%)$, and genitourinary $\quad(\mathrm{n}=10, \% 12.5)$ symptoms. Among those with complaints, seven (8.8\%) were concluded not to be associated with any disease, condition or disorder and the rest were diagnosed with conditions such as infection/ inflammation $(n=26,32.5)$, nephro-urological disorder $(\mathrm{n}=12,15 \%)$, hematological disorder $(n=12,15 \%)$, and neurodevelopmental disorder $(n=11,13.8 \%)$ (Table I, supplementary data).

\section{SARS-CoV-2 IgG seropositivity results}

The seropositivity rate of $\operatorname{IgG}$ antibodies in the collected serum samples was investigated by using Dia.Pro anti-SARS-CoV-2 ELISA IgG kit. Analysis of 80 serum samples revealed only one specimen (patient number 51) with IgG seropositivity $(1.3 \%)$.

\section{Discussion}

Current literature does not have any data on SARS-CoV-2 seropositivity among asymptomatic children in Northern Cyprus. The aim of our study was to fill this gap in the literature by using blood samples collected from children who were admitted to a university hospital with complaints not associated with COVID-19 and no history of a SARS-CoV-2 infection. The study covered a period of five months after the international flight restrictions and school closure implementations were lifted, during which 1,394 subjects were reported positive out of 182,723_molecular tests performed in the country.
Serologic tests were preferred for our investigation as they can detect antibodies produced during both present and past infections. Such serologic studies would provide data for health-care policies, and on the immune status of children in the region. According to the latest data provided by TSI in 2011, the population younger than 20 years of age constituted $25.7 \%(n=73,517)$ of the overall $(\mathrm{n}=286,257)$ TRNC population. ${ }^{11}$

Our study reported 1.3\% IgG seropositivity in the pediatric population. Furthermore, there has not been any multisystem inflammatory syndrome or Kawasaki syndrome cases $^{14}$ observed in the pediatric patient population in the hospital during the time that the study was conducted. The only patient with an IgG+ result was a two-year old girl who had a complaint of anal itching and was diagnosed with parasitosis caused by Enterobius vermicularis. However further testing, such as a neutralization assay, is required to confirm the data due to crossreactivity previously suggested between SARS$\mathrm{CoV}-2$, and parasites. ${ }^{15}$

The asymptomatic seropositivity rate detected in our study is similar to the global seroprevalence previously reported for populations younger than 20 years of age (2.3\%: $1.0-3.6 \%) .{ }^{16}$ Since children are more likely to be infected at home during widespread school closures ${ }^{5}$, the low seropositivity rate is thought to be due to reduced exposure because of the school closure implementation that was in practice between March-September 2020. On the other hand, considering the asymptomatic infection rate among children that ranged between $15 \%$ to $42 \%{ }^{17}$, our data also indicates that children in the country are generally susceptible to SARSCoV-2 infection, and highlights the importance of prevention and control measures for the pediatric population.

In our study, $\operatorname{IgM}$ seropositivity rates were not investigated which underestimates the possible impact of early infections on the seropositivity rate reported. While IgM-based tests were more sensitive in the detection of symptomatic than 
Table I. Clinical characteristics of the pediatric patients.

\begin{tabular}{lc}
\hline Clinical characteristic & $\begin{array}{c}\text { Study group } \\
\mathrm{n}(\%)\end{array}$ \\
\hline Patient & $80(100)$ \\
Gender & \\
Girl & $40(50)$ \\
Boy & $40(50)$
\end{tabular}

Age

Average \pm SD

Range (min - max)

$7.6 \pm 4.0 \mathrm{yrs}$

$2-15 \mathrm{yrs}$

Pre-diagnosed condition*

No pre-diagnosed condition

$49(61.3)$

Allergy

Asthma

Endocrine disorders

Celiac disease

Type-1 diabetes

Gastrointestinal disorders

PFIC

Hematological disorders

Iron deficiency

Neoplasm

Nephro-urological diseases

Chronic kidney disease

IgA nephropathy

Nephrolithiasis

Nutcracker syndrome

Proteinuria

Vesicoureteral reflux

Neurodevelopmental disorders

Attention-deficit/hyperactivity

Cerebral palsy

Developmental delay

Epilepsy

Joubert syndrome

Precocious puberty

$2(2.5)$

Juvenile idiopathic arthritis

PFIC:progressive familial intrahepatic cholestasis "Three patients had mixed underlying conditions.

"One patient had complaints of both nausea and vomiting.

${ }^{+}$Thirteen patients were diagnosed with more than one disorder/infection.
Table I. Continued.

\begin{tabular}{lc}
\hline Clinical characteristic & $\begin{array}{c}\text { Study group } \\
\mathrm{n}(\%)\end{array}$ \\
\hline $\begin{array}{l}\text { Reasons for admission } \\
\text { Routine check-up }\end{array}$ & $17(21.3)$
\end{tabular}

Dermatologic symptoms

Hair loss

Paleness

Soft tissue inflammation

Endocrine symptoms

Overweight

Gastrointestinal symptoms

Abdominal pain

Diarrhea

Nausea

Vomiting

Genitourinary symptoms

Anal itching

Faul smelling urine

Painful urination

Recurrent infection

Urinary incontinence

Neurological symptoms

Headache

Speech delay

Respiratory symptoms

Nasal blockage

Skeletal symptoms

Swelling on foot

Swelling on knee

Swelling on neck

Leg pain

Trauma

Others

Fatigue-malaise

Loss of appetite

Nasal bleeding

$1(1.3)$

PFIC:progressive familial intrahepatic cholestasis

"Three patients had mixed underlying conditions. "One patient had complaints of both nausea and vomiting.

${ }^{+}$Thirteen patients were diagnosed with more than one disorder/infection. 
Table I. Continued.

\begin{tabular}{|c|c|}
\hline Clinical characteristic & $\begin{array}{c}\text { Study group } \\
\mathrm{n}(\%)\end{array}$ \\
\hline \multicolumn{2}{|l|}{ Diagnosis $^{\dagger}$} \\
\hline No diseases & $7(8.8)$ \\
\hline \multicolumn{2}{|l|}{ Allergy } \\
\hline Asthma & $6(7.5)$ \\
\hline Urticaria & $1(1.3)$ \\
\hline \multicolumn{2}{|l|}{ Ear Nose Throat disorder } \\
\hline Nasal polyp & $2(2.5)$ \\
\hline \multicolumn{2}{|l|}{ Endocrine disorders } \\
\hline Obesity & $2(2.5)$ \\
\hline Rickets & $6(7.5)$ \\
\hline \multicolumn{2}{|l|}{ Gastrointestinal disorder } \\
\hline Celiac disease & $1(1.3)$ \\
\hline Constipation & $2(2.5)$ \\
\hline PFIC & $1(1.3)$ \\
\hline \multicolumn{2}{|l|}{ Hematological disorder } \\
\hline Inguinal lymphadenitis & $1(1.3)$ \\
\hline Iron deficiency anemia & $9(11.3)$ \\
\hline Lymphadenitis & $1(1.3)$ \\
\hline Neoplasm & $1(1.3)$ \\
\hline \multicolumn{2}{|l|}{ Infection/inflammation } \\
\hline Cellulitis & $1(1.3)$ \\
\hline Gastroenteritis & $12(15)$ \\
\hline Parasitosis & $2(2.5)$ \\
\hline Urinary tract infection & $11(13.8)$ \\
\hline \multicolumn{2}{|l|}{ Nephro-urological disorder } \\
\hline Chronic kidney disease & $2(2.5)$ \\
\hline Diabetic nephropathy & $1(1.3)$ \\
\hline IgA nephropathy & $2(2.5)$ \\
\hline Nephrolithiasis & $2(2.5)$ \\
\hline Nutcracker syndrome & $2(2.5)$ \\
\hline Nonorganic enuresis & $1(1.3)$ \\
\hline Proteinuria & $1(1.3)$ \\
\hline Vesicoureteral reflux & $1(1.3)$ \\
\hline \multicolumn{2}{|l|}{ Neurodevelopmental disorder } \\
\hline Attention-deficit/hyperactivity & $2(2.5)$ \\
\hline Cerebral palsy & $1(1.3)$ \\
\hline Developmental delay & $1(1.3)$ \\
\hline Epilepsy & $4(5)$ \\
\hline Joubert syndrome & $1(1.3)$ \\
\hline Precocious puberty & $2(2.5)$ \\
\hline \multicolumn{2}{|l|}{$\begin{array}{l}\text { Rheumatologic - Orthopedic } \\
\text { disorder }\end{array}$} \\
\hline Juvenile idiopathic arthritis & $2(2.5)$ \\
\hline Trauma & $2(2.5)$ \\
\hline
\end{tabular}

PFIC:progressive familial intrahepatic cholestasis *Three patients had mixed underlying conditions. "One patient had complaints of both nausea and vomiting. ${ }^{+}$Thirteen patients were diagnosed with more than one disorder/infection. asymptomatic SARS-CoV-2 infections ${ }^{12}$, this could be due to delayed sampling time as it is difficult to identify the onset of the asymptomatic infection. Furthermore, in a recent study, detection of IgM and IgG antibodies, especially in combination with nucleic acid-based tests and pulmonary computed tomography, was suggested as a preferred method for detection of asymptomatic SARS-CoV-2 infections. ${ }^{18}$ Screening for SARS-CoV-2-specific IgA antibodies can also be considered for future studies since like IgM, IgA production starts and peaks within the first 7 days of infection. ${ }^{19}$

In our study, because of its retrospective nature, it was not possible to collect molecular and/or serological data from other family members and investigate the effects of asymptomatic children on SARS-CoV-2 transmission. Therefore, future community-based studies with the inclusion of subjects of different ages at multiple time points would not only contribute to the relevant literature on the role played by asymptomatic children, but also influence policy decisions during the pandemic in Northern Cyprus.

In addition to the limitations described above, another limitation that prevented us from drawing comprehensive conclusions in our study was the low sample size. Furthermore, since asymptomatic patients are unlikely to be hospitalized, community-based studies are recommended for the estimation of the actual asymptomatic infection rate among the pediatric population in the country.

To conclude, our study reported an asymptomatic SARS-CoV-2 seropositivity rate of $1.3 \%$ among children in Northern Cyprus, which can further increase due to the lifting of school closure implementation. Therefore, rapid antigen or RT-PCR tests that may be performed along with serological assays $\mathrm{s}^{20,21}$ are recommended to continuously monitor SARS$\mathrm{CoV}-2$ infection among the pediatric population for the control of COVID-19 spread in the country. 


\section{Ethical approval}

Near East University (NEU) Scientific Research and Evaluation Ethics Committee (Project No: YDU/2020/86-1226)

\section{Author contribution}

The authors confirm contribution to the paper as follows: study conception and design: TS; data collection: UG, AAS, ER, BS, CD, IB, KS, ND; analysis and interpretation of results: UG, AAS, ER, MS, TS; draft manuscript preparation: UG. All authors reviewed the results and approved the final version of the manuscript.

\section{Conflict of interest}

The authors declare that there is no conflict of interest.

\section{REFERENCES}

1. Sultanoglu N, Baddal B, Suer K, Sanlidag T. Current situation of COVID-19 in northern Cyprus. East Mediterr Health J 2020; 26: 641-645. https://doi. org/10.26719/emhj.20.070

2. Turkish Republic of Norhtern Cyprus, Ministry of Health. Available at: https://saglik.gov.ct.tr/COVID19-GENEL-DURUM (Accessed on December 28, 2021).

3. Viner RM, Russell SJ, Croker H, et al. School closure and management practices during coronavirus outbreaks including COVID-19: a rapid systematic review. The Lancet Child Adolesc Health 2020; 4: 397404. https://doi.org/10.1016/S2352-4642(20)30095-X

4. Li X, Xu W, Dozier M, He Y, Kirolos A, Theodoratou $\mathrm{E}$. The role of children in transmission of SARSCoV-2: a rapid review. J Glob Health 2020; 10: 011101. https://doi.org/10.7189/jogh.10.011101

5. Hyde Z. Difference in SARS-CoV-2 attack rate between children and adults may reflect bias. Clin Infect Dis 2022; 74: 152-155. https://doi.org/10.1093/ cid/ciab183
6. Mensah AA, Sinnathamby M, Zaidi A, et al. SARSCoV-2 infections in children following the full re-opening of schools and the impact of national lockdown: prospective, national observational cohort surveillance, July-December 2020, England. J Infect 2021; 82: 67-74. https://doi.org/10.1016/j. jinf.2021.02.022

7. Ratmann O, Bhatt S, Flaxman S. Implications of a highly transmissible variant of SARS-CoV-2 for children. Arch Dis Child 2021; 106: e37. https://doi. org/10.1136/archdischild-2021-321903

8. Williams PCM, Howard-Jones AR, Hsu P, et al. SARS$\mathrm{CoV}-2$ in children: spectrum of disease, transmission and immunopathological underpinnings. Pathology 2020; 52: 801-808. https://doi.org/10.1016/j. pathol.2020.08.001

9. Oran DP, Topol EJ. Prevalence of asymptomatic SARS-CoV-2 infection. Ann Internl Med 2021; 174: 286-287. https://doi.org/10.7326/L20-1280

10. Lauring AS, Hodcroft EB. Genetic variants of SARSCoV-2 - What do they mean? JAMA 2021; 325: 529531. https://doi.org/10.1001/jama.2020.27124

11. KKTC İstatistik Kurumu. KKTC Nüfus Sayımı 2011. Available at: http://www.stat.gov.ct.tr/nufus2011. aspx (Accessed on December 28, 2021)

12. Al-Jighefee HT, Yassine HM, Nasrallah GK. Evaluation of antibody response in symptomatic and asymptomatic covid-19 patients and diagnostic assessment of new IgM/IgG elisa kits. Pathogens 2021; 10: 161. https://doi.org/10.3390/pathogens10020161

13. Cramer A, Goodman N, Cross T, Gant V, Dziadzio M. Analytical evaluation and critical appraisal of early commercial SARS-CoV-2 immunoassays for routine use in a diagnostic laboratory. Br J Biomed Sci 2021; 78: 141-146. https://doi.org/10.1080/096748 45.2020.1864108

14. Rehman S, Majeed T, Ansari MA, Al-Suhaimi EA. Syndrome resembling Kawasaki disease in COVID-19 asymptomatic children. J Infect Public Health 2020; 13: 1830-1832. https://doi.org/10.1016/j. jiph.2020.08.003

15. Iesa MAM, Osman MEM, Hassan MA, et al. SARSCoV-2 and Plasmodium falciparum common immunodominant regions may explain low COVID-19 incidence in the malaria-endemic belt. New Microbes New Infect 2020; 38: 100817. https:// doi.org/10.1016/j.nmni.2020.100817 
16. Rostami A, Sepidarkish M, Leeflang MMG, et al. SARS-CoV-2 seroprevalence worldwide: a systematic review and meta-analysis. Clin Microbiol Infect 2021; 27: 331-340. https://doi.org/10.1016/j. cmi.2020.10.020

17. Viner RM, Ward JL, Hudson LD, et al. Systematic review of reviews of symptoms and signs of COVID-19 in children and adolescents. Arch Dis Child 2021; 106: 802-807. https://doi.org/10.1136/ archdischild-2020-320972

18. Li Y, He Q, Yu R, et al. Highlighted prospects of an $\operatorname{IgM} / \operatorname{IgG}$ antibodies test in identifying individuals with asymptomatic severe acute respiratory syndrome coronavirus 2 (SARS-CoV-2) infection. Arch Pathol Lab Med 2021; 145: 39-45. https://doi. org/10.5858/arpa.2020-0310-SA
19. Nuccetelli M, Pieri M, Gisone F, Bernardini S. Combined anti-SARS-CoV-2 $\operatorname{Ig} \mathrm{A}, \operatorname{IgG}$, and $\operatorname{IgM}$ detection as a better strategy to prevent second infection spreading waves. Imunol Invest 2020; 1-13. https://doi.org/10.1080/08820139.2020.1823407

20. Machado BAS, Hodel KVS, Barbosa-Júnior VG, Soares MBP, Badaró R. The main molecular and serological methods for diagnosing covid-19: an overview based on the literature. Viruses 2020; 13: 40. https://doi.org/10.3390/v13010040

21. La Marca A, Capuzzo M, Paglia T, Roli L, Trenti T, Nelson SM. Testing for SARS-CoV-2 (COVID-19): a systematic review and clinical guide to molecular and serological in-vitro diagnostic assays. Reprod Biomed Online 2020; 41: 483-499. https://doi. org/10.1016/j.rbmo.2020.06.001 